\section{Endoscopic features of an adenoid cystic carcinoma of the esophagus: narrow-band imaging and dual focus magnification}

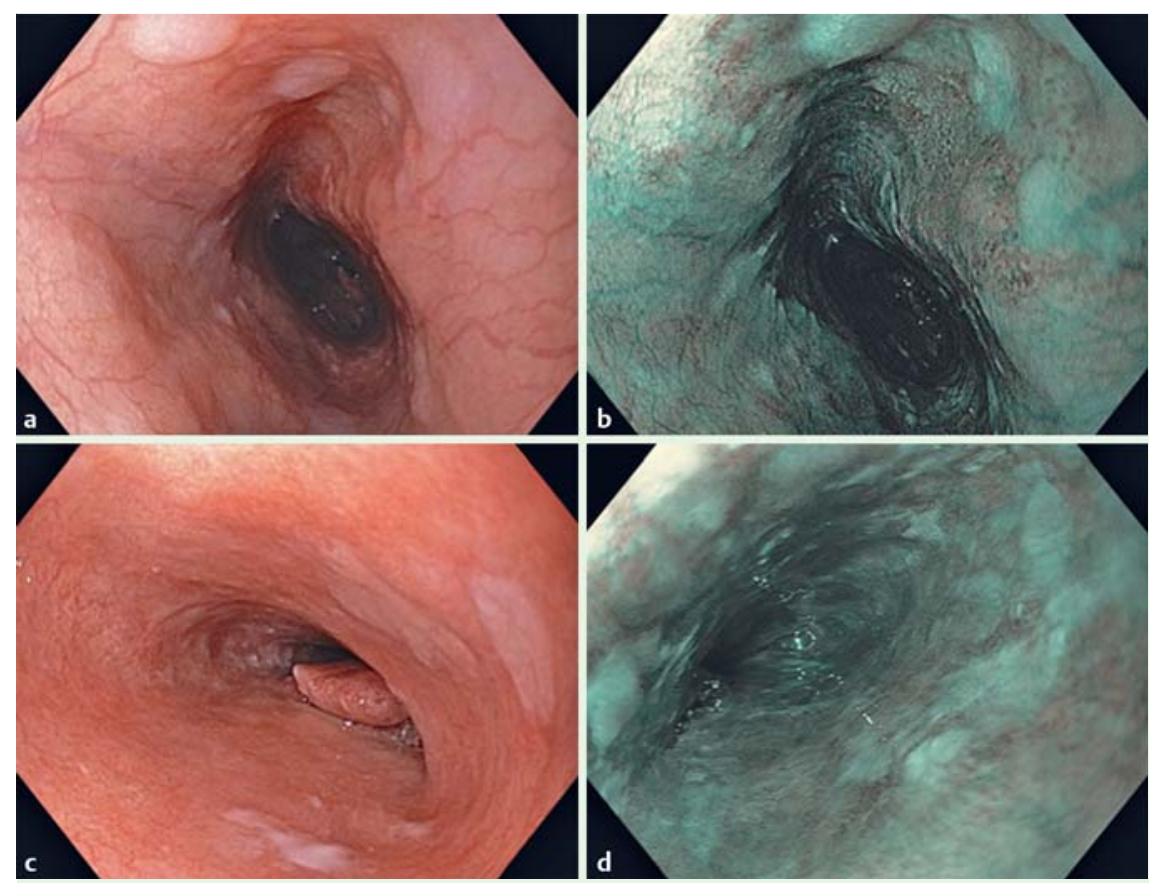

Fig. 1 Endoscopic views of the mid-esophageal lesion. a White-light far view of the upper edge of the lesion. b Narrow-band imaging (NBI) of the upper edge of the lesion. $\mathbf{c}$ White-light far view of the polypoid component. $\mathbf{d ~ N B I}$ of the lower flat component between 39 and $41 \mathrm{~cm}$ from the dental arch.

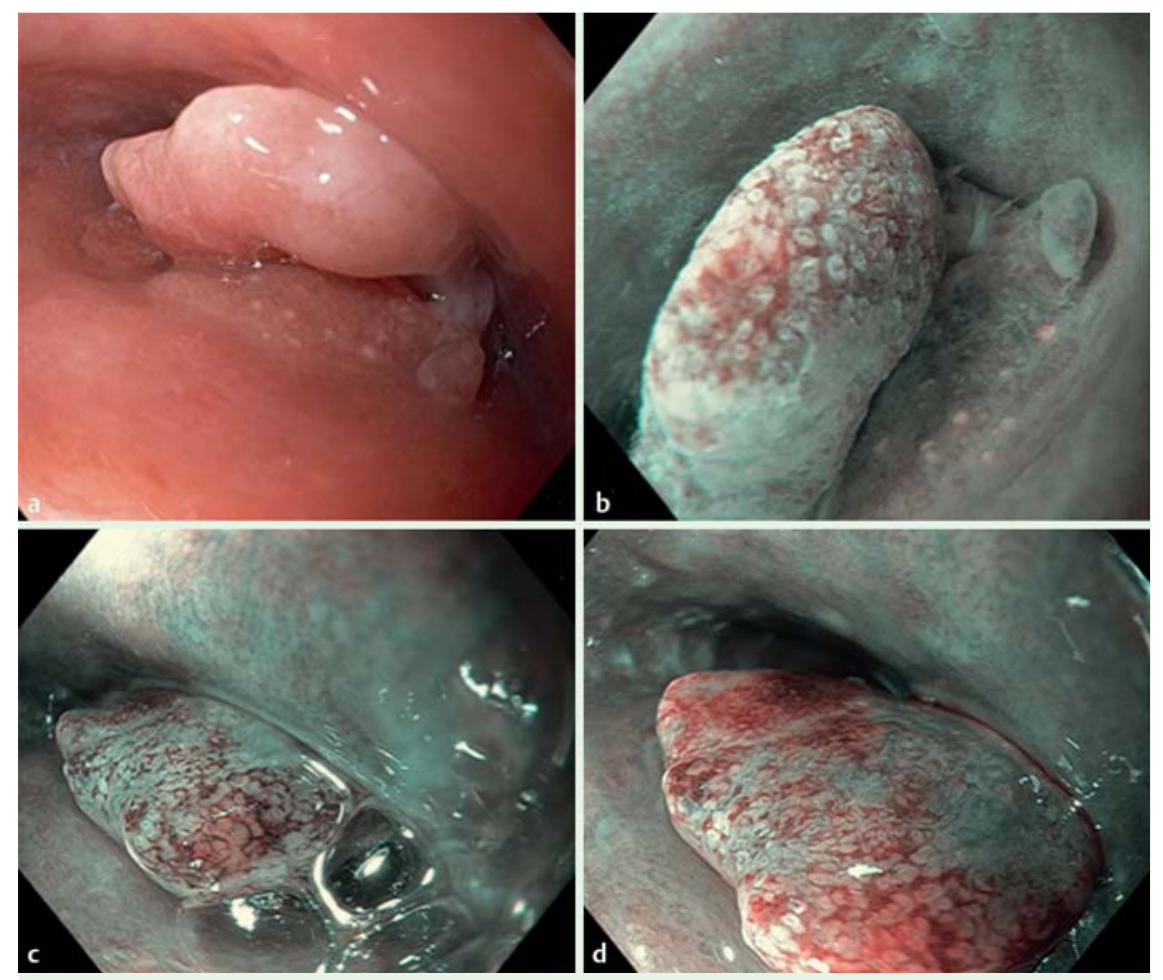

Fig.2 Endoscopic features of the polypoid component included: a the pale pink color of the pedunculated component; $\mathbf{b}$ a pseudoglandular appearance using narrow-band imaging (NBI) and dual-focus magnification; $\mathbf{c}, \mathbf{d}$ a regular vascular pattern surrounding glandular whitish components.
Endoscopic examination with virtual chromoendoscopy is currently the best way to distinguish squamous cell carcinoma and adenocarcinoma in the esophagus $[1,2]$. However, some unusual tumors such as adenoid cystic carcinoma can have atypical endoscopic features.

A 65-year-old man was referred because of an atypical esophageal neoplastic lesion. A gastroscopy had first been performed for a 3-month history of dysphagia and detected a 1-cm polyp in the mid-esophagus. A biopsy sample from this polyp showed atypical adenocarcinoma and he was therefore referred for evaluation with white-light, narrow-band imaging (NBI), and magnification endoscopy (GIFHQ190; Olympus, Tokyo, Japan) ( Fig. 1, - Video 1).

We detected a flat brownish circumferential lesion, at $26-42 \mathrm{~cm}$ from the dental arch, surrounding the polypoid lesion, which was located at $30 \mathrm{~cm}$. The polypoid component showed a regular mucosal pattern with white "villous" structures surrounded with brown vessels indicating a glandular pattern ( $\bullet$ Fig. 2 ). In the flat component, the mucosal pattern had the appearance of a squamous cell carcinoma with the brownish flat lesion and irregular thick capillary loops [3] ( $\bullet$ Fig. 3). This area was iodo-negative. Endoscopic ultrasound (EUS) found several suspect lymph nodes in the mediastinum. We then confirmed the atypical features with a new biopsy that reported an atypical carcinoma with both glandular and squamous features.

Finally, the patient was referred for an esophagectomy after a transnasal endoscopy (GIF N180; Olympus) had been performed to precisely define the upper margin ( Fig.4). Final histology of the surgical specimen was reported as an adenoid cystic epidermoid carcinoma $[4,5]$ with a basaloid squamous component infiltrating the muscular layer and with Pagetoid spread into the squamous epithelium (๑ Fig. 5).

Adenoid cystic carcinoma is a rare esophageal cancer with large lateral extension. Endoscopic features are a mix of glandular and squamous characteristics and the diagnosis is mainly based on the biopsy samples, which show both glandular and squamous cell carcinoma features. Particular attention must be paid, using virtual chromoendoscopy and magnification, to the precise margins of the lesion.

Endoscopy_UCTN_Code_CCL_1AB_2AC_3AB 

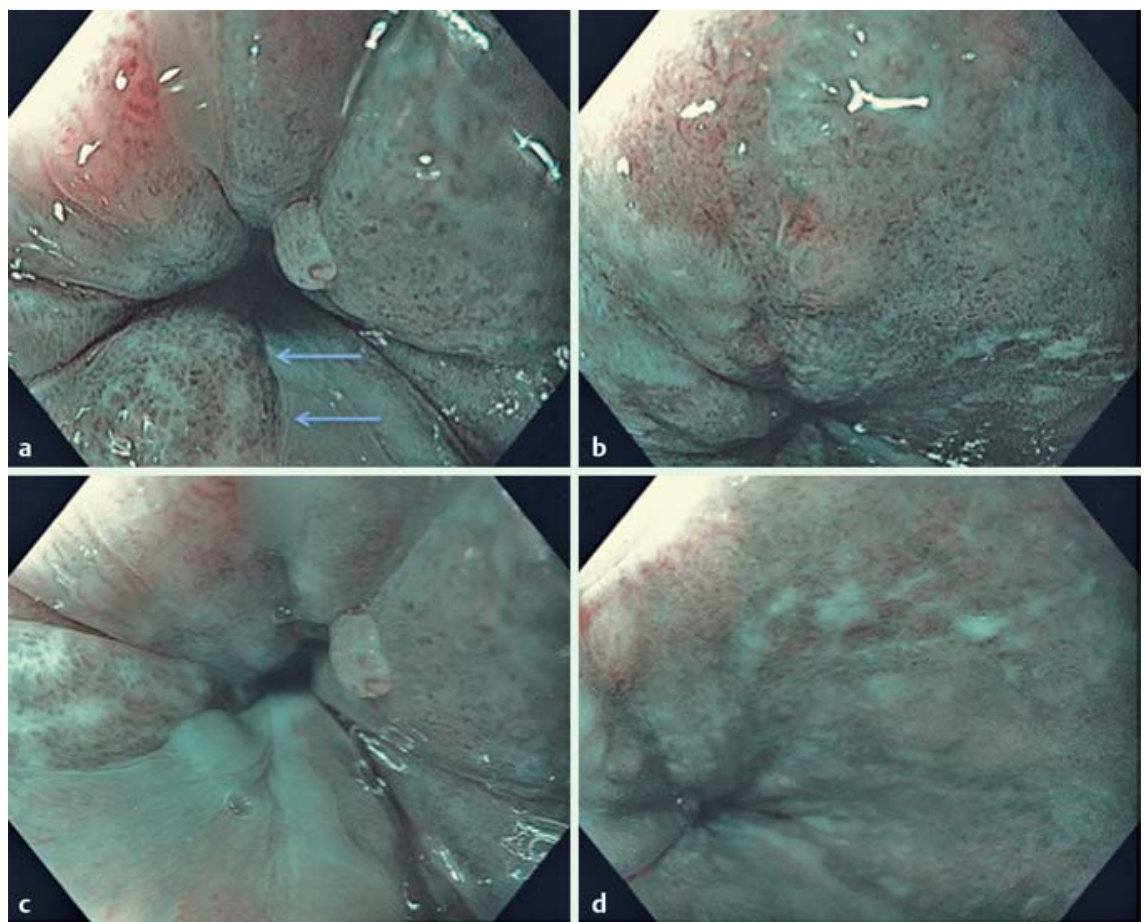

Fig. 3 Endoscopic features of the flat component on narrow-band imaging (NBI) included: $\mathbf{a}$ an irregular vascular pattern (big vessels) and a clear demarcation line (arrows) with the normal squamous epithelium; $\mathbf{b}$ an irregular mucosal pattern with mucous and nodular components; $\mathbf{c}, \mathbf{d}$ an irregular unclear pattern on non-magnified view.
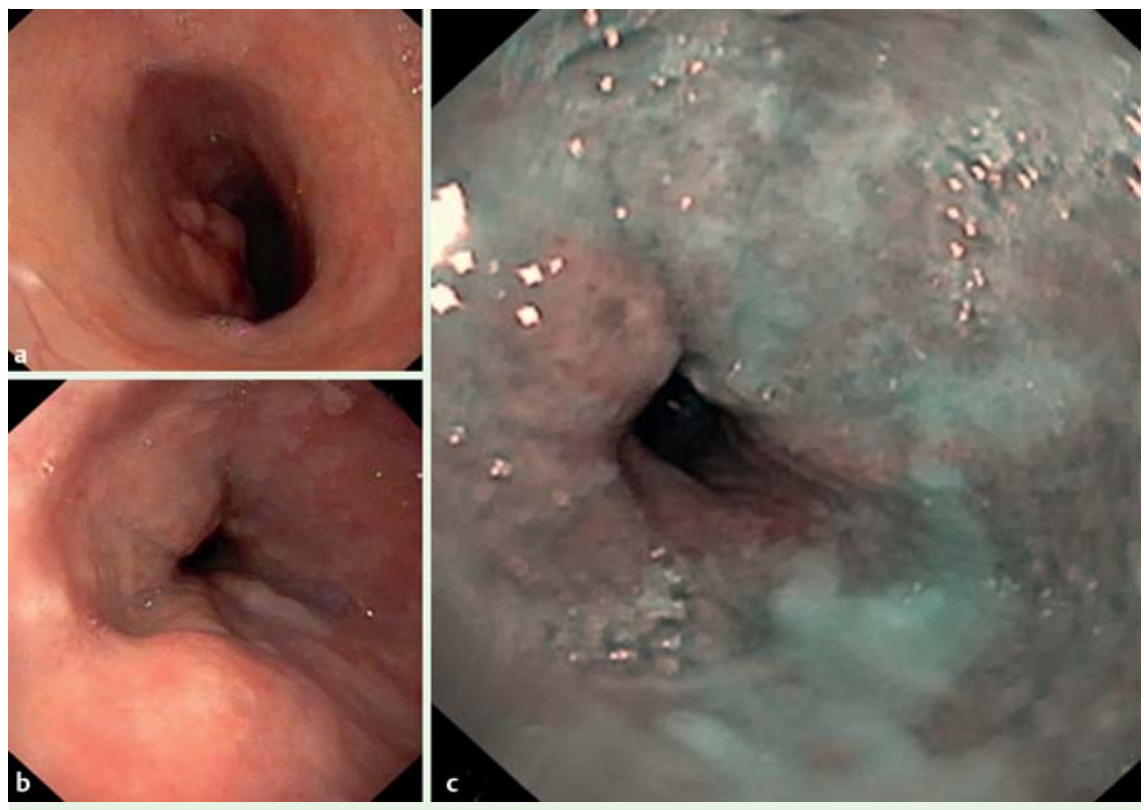

Fig.4 Transnasal endoscopic features with: a, b white-light endoscopy; c narrow-band imaging (NBI).

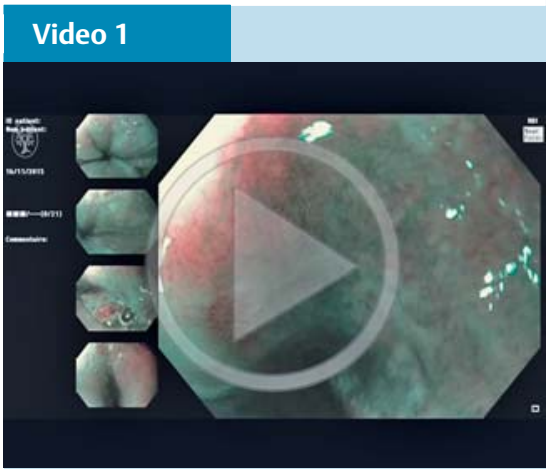

Endoscopic features of the adenoid cystic carcinoma in the mid-esophagus.

\section{Competing interests: None}

\section{Franck Nicolas Bardou', Jérôme Rivory ${ }^{1}$, Maud Robert ${ }^{2}$, Diane Collet Benzaquen $^{3}$, Jean-François Fléjou ${ }^{4}$, Thierry Ponchon ${ }^{1}$, Mathieu Pioche ${ }^{1}$}

${ }^{1}$ Department of Endoscopy and Gastroenterology, Pavillon L, Edouard Herriot Hospital, Lyon, France

2 Department of Digestive Surgery, Pavillon D, Edouard Herriot Hospital, Lyon, France

${ }^{3}$ Department of Pathology, Edouard Herriot Hospital, Lyon, France

${ }^{4}$ Department of Pathology, Saint Antoine Hospital, Assistance Publique - Hôpitaux de Paris, France

\section{References}

1 Wolfsen HC, Crook JE, Krishna M et al. Prospective, controlled tandem endoscopy study of narrow band imaging for dysplasia detection in Barrett's esophagus. Gastroenterology 2008; 135: 24-31

2 Takenaka R, Kawahara Y, Okada $\mathrm{H}$ et al. Narrow-band imaging provides reliable screening for esophageal malignancy in patients with head and neck cancers. Am J Gastroenterol 2009; 104: 2942-2948

3 Kumagai Y, Inoue H, Nagai Ket al. Magnifying endoscopy, stereoscopic microscopy, and the microvascular architecture of superficial esophageal carcinoma. Endoscopy 2002; 34: 369-375

4 Sawada G, Moon J, Saito A et al. A case of adenoid cystic carcinoma of the esophagus. Surg Case Rep 2015; 1: 119. Available from: http://www.ncbi.nlm.nih.gov/pmc/articles/ PMC4662665/

5 Kai $Y$, Kato M, Hayashi $Y$ et al. Esophageal early basaloid squamous carcinoma with unusual narrowband imaging magnified endoscopy findings. World J Gastroenterol 2014; 20: 12673-12677 


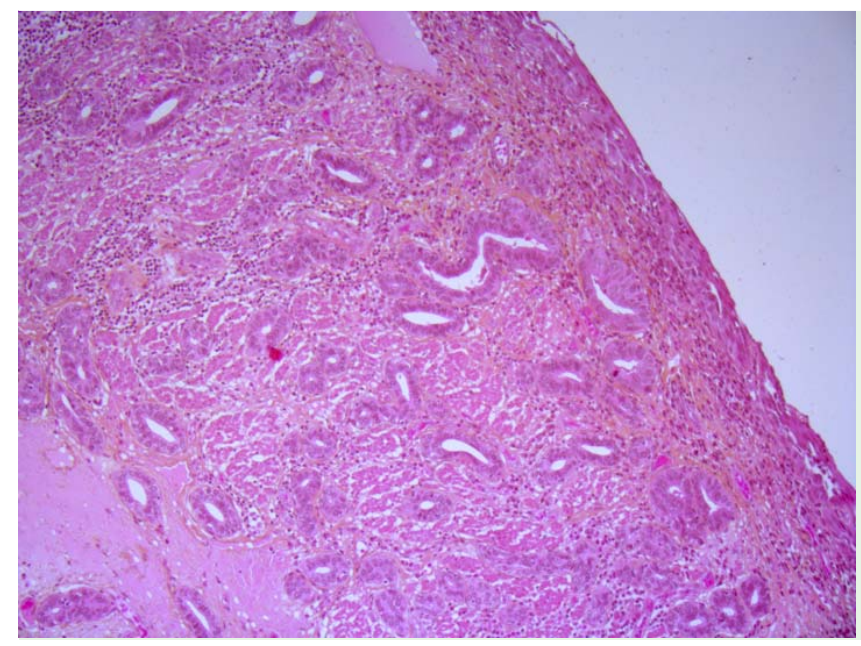

Fig.5 Histology showing an adenoid cystic epidermoid carcinoma with basaloid squamous component.

\section{Bibliography}

DOI http://dx.doi.org/

10.1055/s-0042-118167

Endoscopy 2016; 48: E380-E382

(c) Georg Thieme Verlag KG

Stuttgart · New York

ISSN 0013-726X

\section{Corresponding author}

\section{Mathieu Pioche, MD}

Endoscopy unit - Digestive Disease Department Pavillon L - Edouard Herriot Hospital

69437 Lyon

France

mathieu.pioche@chu-lyon.fr 